\title{
Graphene Inkjet-Printed Ultrawideband Tapered Coplanar-Waveguide Antenna on Kapton Substrate
}

\author{
Isidoro Ibanez-Labiano ${ }^{1 *}$ and Akram Alomainy ${ }^{1}$ \\ ${ }^{1}$ School of Electronic Engineering and Computer Science, Queen Mary University of London, London E1 4NS, UK \\ *i.ibanezlabiano@qmul.ac.uk
}

\begin{abstract}
This paper presents an ultra-wideband graphene antenna with tapered coplanar-waveguide feed. The proposed antenna covers the $2.7-8.2 \mathrm{GHz}$ bandwidth $(2.6-10 \mathrm{GHz}$ measured), with two main resonance frequencies at 3.1 and 5.5 gigahertz (3.1 and 5.8 measured). Simulations show a radiation pattern that looks quasi-omnidirectional with a maximum gain limited to $3.15 \mathrm{dBi}$ and efficiency above $84.7 \%$. In order to post-process the graphene ink and to provide flexibility, Kapton Polyimide is used as a substrate. The flexibility, as well as the lightweight and ease in the fabrication of accurate designs, turns this antenna into a suitable candidate for wearable and flexible wireless applications.
\end{abstract}

Index Terms-flexible antenna, UWB, CPW feed, inkjet, graphene.

\section{INTRODUCTION}

Wearable wireless technology is a hot topic at present and with a promising forecast for the near future [1]. Wearable devices can play a key role in the development of a wide range of applications among sports analytics [2], positioning systems [3], and healthcare [4]. Flexible antennas play a key role within wearable systems, allowing the user to freely enjoy the system without constraining the user activity and causing the minimum disturbance.

The dynamic environment of body-centric devices requires compact, low-profile, and flexible devices. Novel solutions should explore flexible materials, remaining ergonomic and comfortable, but can endure being worn by a subject. Among these solutions, carbon-based materials such as graphene are a very promising eco-friendly candidate, due to their unique properties and characteristics [5]. Graphene is a two-dimensional (2D) carbon crystal, it is an atomic-scale hexagonal lattice made of carbon atoms, in a honeycomb pattern. It has exceptional electrical conductivity to allow the spread of high-frequency signals [6]. Graphene-based gadgets are effective in developing flexible, conformal, or even stretchable options in any application [7]. Recent progress in graphene fabrication processes suggests a feasible future for the use of this technology in several fields.

Together with these innovative materials novel fabrication methods should be explored. Additive manufacturing processes have raised as accurate and lowcost procedures and among them two printing techniques: screen printing and inkjet printing [8-11]. Inkjet printing is an additive electronic fabrication method that has been attracting a lot of attention for both research and commercial applications as a highly scalable and environmentally friendly alternative to more conventional fabrication schemes
[12]. It allows multilayer fabrication onto any rigid or flexible substrate.

This work proposes a conformal wearable antenna in the microwave band, fabricated by inkjet printing carbon-based inks onto flexible substrates such as Kapton films.

\section{ANTENNA DESIGN AND MATERIALS}

\section{A. Antenna Design}

The designed antenna consists of a UWB antenna model with a tapered coplanar-waveguide (TCPW) feed [13-15]. The model employs a simple CPW feed, therefore, easing the often complex feeding network, suitable for inkjet printing. Furthermore, it offers a consistent characteristic impedance over a wide range of bandwidth (BW) [16]. A 3-D CAD model is shown in Fig. 1 (a), where its geometry defines operational bandwidth. The width of the antenna is $16 \mathrm{~mm}$ $\left(0.28 \lambda_{\mathrm{g}}\right)$ and the length of the antenna is $27 \mathrm{~mm}\left(0.47 \lambda_{\mathrm{g}}\right)$ where $\lambda_{\mathrm{g}}$ is the wavelength at $3 \mathrm{GHz}$. The slot follows an exponential curve, in cartesian coordinates:

$$
y=s e^{r x}
$$

where $s$ indicates the gap from the feeding pin.
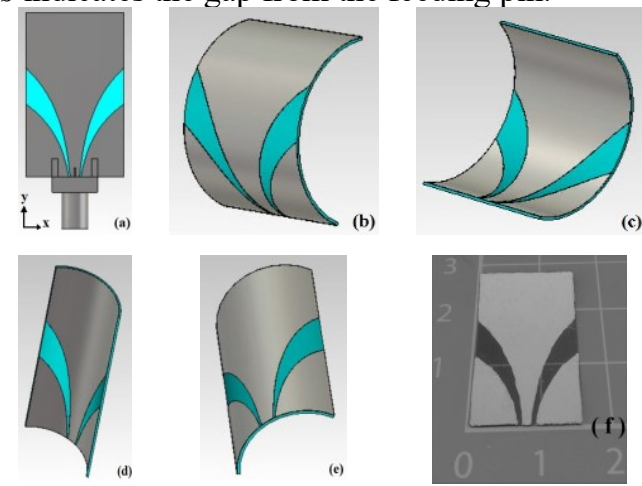

Fig. 1. 3-D CAD model representation of the antenna (a) front view with SMA connector attached; (b) X-convex; (c) X-concave; (d) Y-concave; (e) Y-convex and (f) fabricated prototype.

Graphene ink (793663) from Sigma-Aldrich with 30 dyn/cm surface tension and a particle size smaller than $3 \mu \mathrm{m}$, compatible with the inkjet printing process (Dimatix-2800) was employed. It reaches conductivity values of $2.5 \times 10^{4} \pm$ $0.2 \times 10^{4} \mathrm{~S} / \mathrm{m}$, after optimizing an annealing time of $20 / 30$ $\min$ at $250 / 350{ }^{\circ} \mathrm{C}$ [17]. For the antenna realization, Kapton polyimide-based substrate has been chosen due to their excellent thermal, chemical, mechanical, and electrical properties [18-20]. It can withstand the temperatures for the 
annealing process, but such films feature an inert and highly hydrophobic surface so a pre-treatment with plasma is necessary. Kapton polyimide film with a dielectric constant $\left(\varepsilon_{r}\right)$ of 3.4 , loss tangent $(\tan \delta)$ of 0.002 , and a substrate height of $125 \mu \mathrm{m}$ was employed.

\section{ANTENNA PERformanCE ANALYSES}

The antenna performance is evaluated by the numerical analysis (2019 CST Microwave Studio software) of Sparameters, bending performance, radiation pattern, realized gain, and efficiency.

\section{A. Impedance matching}

Fig. 2 displays the simulated value of the S11 parameter, covering the complete $2.7-8.2 \mathrm{GHz}$ band, with resonant frequencies at 3.1 and $5.5 \mathrm{GHz}$. While previous inkjetprinted graphene antennas were narrowband [21]. Graphene and PEC comparison exhibits consistently similar behaviour for both cases. Measurements results show a $7.4 \mathrm{GHz} \mathrm{BW}$, 2.6-10 GHz band, with resonant frequencies at 3.07 and 5.8 $\mathrm{GHz}$. Good agreement between simulations and measurement was achieved.

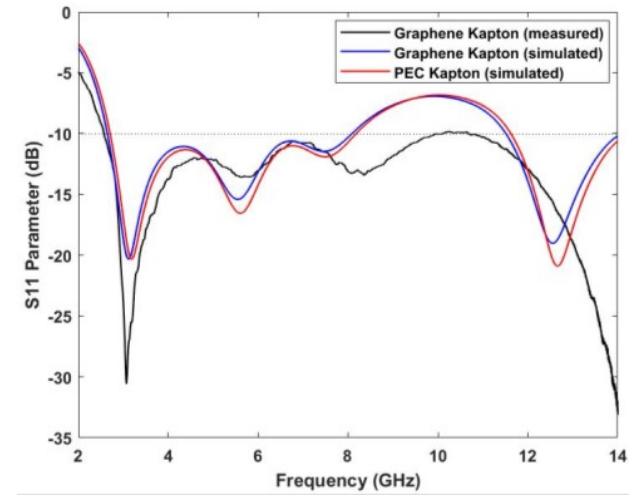

Fig. 2. Comparison of S11 Parameter between Graphene and PEC (simulated) of the proposed antenna model and Graphene (measured).

\section{B. Bending Conditions}

Four bending scenarios were considered in Fig 3. A cylinder with a radius of $35 \mathrm{~mm}$ has been used for the four cases analysis, as it shows in Fig. 1 (b-e).

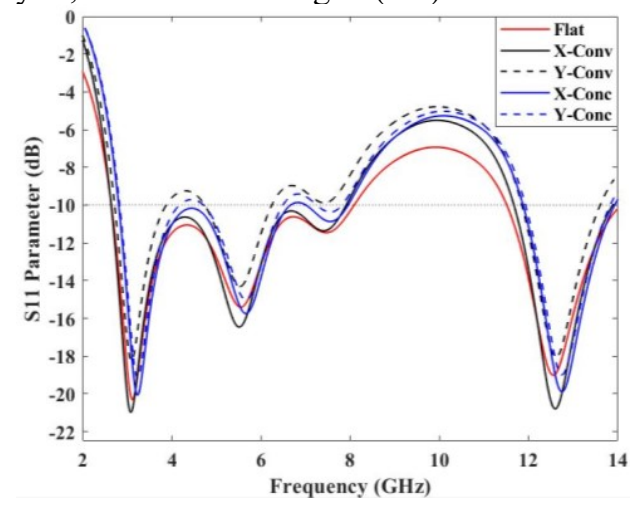

Fig. 3. Simulated S11 Parameter for flat and four bending scenarios.
It has been observed from the parametric analyses that the antenna onto the Kapton substrate is showing almost the same result in all four cases plus the initial (flat) situation. It is an expected result as it was previously simulated in recent research works [22, 23]. Fig 4. shows the experimental results, with behaviour as simulated for both positions (convex and concave) in the $\mathrm{X}$-axis. While for the $\mathrm{Y}$-axis, tends towards lower frequencies and increasing the depth of the valley around $8 \mathrm{GHz}$. This variation is due to the physical tension generated at the interface between the antenna connector.

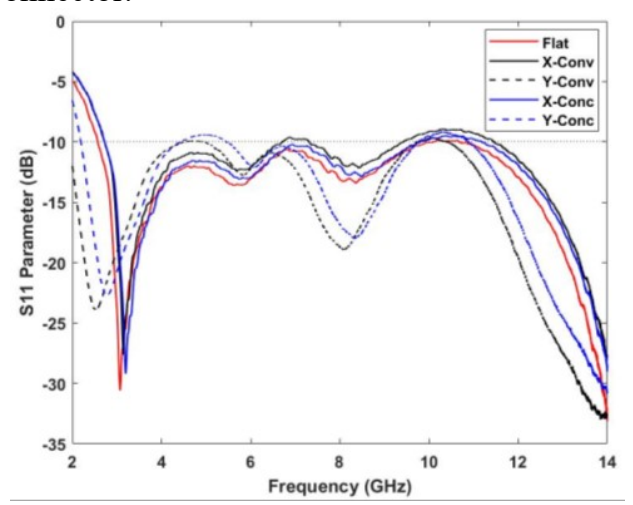

Fig. 4. Measured S11 Parameter for flat and four bending scenarios.

\section{Surface Current Distribution}

The surface current distribution at the resonating frequencies helps to understand the performance of a multiband antenna. The current distribution is shown in Fig. 4(a-d). Fig. 4 (a) shows that at $3 \mathrm{GHz}$, the current is concentrated around the TCPW feed whereas at $5.5 \mathrm{GHz}$ (Fig. 4 (b)) and $6 \mathrm{GHz}$ (Fig. 4 (c)) more current concentration is on the radiating patch.

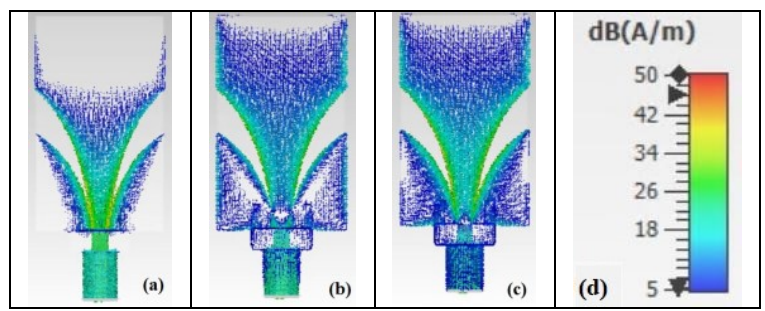

Fig. 5. Simulated Surface Current at (a) 3; (b) 5.5 ; (c) $6 \mathrm{GHz}$ and (d) Scale.

\section{Radiation Pattern}

Maximum radiation in broadside direction can be observed from the simulated E-plane $\left(\varphi=90^{\circ}\right)$ and H-plane $(\varphi$ $=0^{\circ}$ ) of the presented antenna prototype. An omnidirectional pattern for $3 \mathrm{GHz}$ and a quasi-omnidirectional patterns at 5.5, and $6 \mathrm{GHz}$ are shown in Fig. 5 and Fig. 6. These monopole-like radiation patterns, respectively making it compatible with diverse wireless communications applications.

The numerically calculated realized gain along with the peak efficiency for four frequencies are listed in Table I. 
Where it can be seen a peak realized gain of $3.15 \mathrm{dBi}$ for the highest frequency case $(6 \mathrm{GHz})$ and a minimum efficiency of $84.7 \%$. Realized gain values at 3 and $6 \mathrm{GHz}$ are lower than reference values at similar frequencies [15]. On the other hand, simulated estimations of efficiency $(84.7 \%)$ are higher than previously reported values of $47.7 \%$ [24] or $48.6 \%$ at $5.5 \mathrm{GHz}[25]$.

TABLE I. FARFIELD PROPERTIES

\begin{tabular}{|c|c|c|c|c|}
\hline \multicolumn{3}{|c|}{$\begin{array}{c}\text { Graphene + Kapton } \\
\text { This research work }\end{array}$} & \multicolumn{2}{c|}{$\begin{array}{c}\text { Copper + RT Duroid } \\
\text { Reference work [15] }\end{array}$} \\
\hline $\begin{array}{c}\text { Frequency } \\
\text { (GHz) }\end{array}$ & $\begin{array}{c}\text { Realized } \\
\text { Gain (dBi) }\end{array}$ & $\begin{array}{c}\text { Efficie } \\
\text { ncy } \\
(\%)\end{array}$ & $\begin{array}{c}\text { Frequency } \\
\text { (GHz) }\end{array}$ & $\begin{array}{c}\text { Realized } \\
\text { Gain } \\
\text { (dBi) }\end{array}$ \\
\hline 3 & 1.37 & 88 & 3.4 & 1.9 \\
\hline 5.5 & 2.91 & 89 & 5 & 2.9 \\
\hline 6 & 3.15 & 84.7 & 5.8 & 3.6 \\
\hline
\end{tabular}

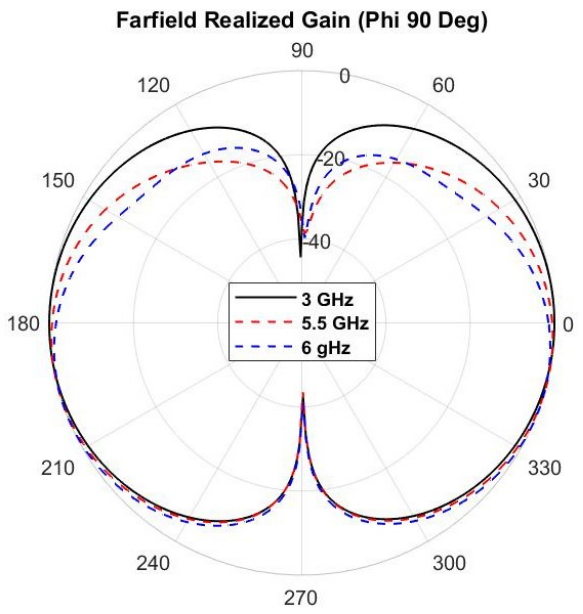

Fig. 6. Simulated radiation pattern of the proposed graphene-based antenna; E-plane cut, at $\varphi=90^{\circ}$.

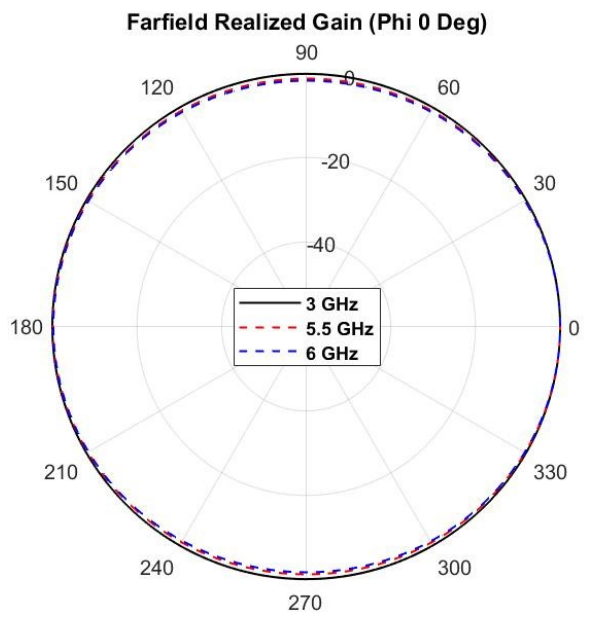

Fig. 7. Simulated radiation pattern of the proposed graphene-based antenna; H-plane cut, at $\varphi=0^{\circ}$.

\section{CONCLUSION}

A flexible UWB TCPW graphene antenna working at microwave frequencies is presented and analysed. The measured antenna has attained a total impedance bandwidth of $7.4 \mathrm{GHz}$ ranging from 2.6 to $10 \mathrm{GHz}$. The omnidirectional radiation has been observed due to the coplanar structure. The simulated results have shown a peak realized gain of the antenna $\sim 3.15 \mathrm{dBi}$, similar to previously reported in the literature, with an antenna efficiency above $84 \%$. The Kapton substrate allows the annealing process of the graphene ink, resulting in a proposed flexible, compact, lightweight, and robust design along with good radiation characteristics. The suggested antenna has potential in advanced materials devices, suitable for various wireless applications for future conformal and flexible electronic devices. Further experimental analyses are required with respect to this point.

\section{ACKNOWLEDGMENT}

This research was supported by the School of EECS, Queen Mary University of London.

\section{REFERENCES}

[1] IDTechEx, "Wearable Technology 2016-2026," Available: [Online], IDTechEx.

[2] S. Minyoung, "Chapter 12 - Wearable sensors for athletes," Electronic Textiles: Smart Fabrics and Wearable Technology. Woodhead Publishing, 2015.

[3] S. Jaspreet and K. Payal, "High Gain Textile Rectangular Microstrip Patch Antenna design employing Denim Substrate for Satellite Space to Earth downlink applications," ICGTSPICC, 2016.

[4] M. M. Bait-Suwailam, I. Labiano, and A. Alomainy, "Impedance Enhancement of Textile Grounded Loop Antenna Using HighImpedance Surface (HIS) for Healthcare Applications," Sensors, vol. 20, no. 14, pp. 3809, 2020.

[5] T. Palacios, A. Hsu, and H. Wang, "Applications of graphene devices in RF communications," IEEE Commun. Mag., vol. 48, no. 6, pp. 122-128, Jun. 2010.

[6] A. C. Ferrari et al., "Science and technology roadmap for graphene, related two-dimensional crystals, and hybrid systems," Nanoscale, vol. 7, no. 11, pp. 4598-4810, 2015.

[7] F. Rana, "Graphene Terahertz Plasmon Oscillators," IEEE Transactions on Nanotechnology, vol. 7, no. 1, pp. 91-99, Jan. 2008.

[8] M. L. Scarpello, I. Kazani, C. Hertleer, H. Rogier and D. Vande Ginste, "Stability and Efficiency of Screen-Printed Wearable and Washable Antennas," in IEEE Antennas and Wireless Propagation Letters, vol. 11, pp. 838-841, 2012.

[9] G. G. Xiao, Z. Zhang, S. Lang and Y. Tao, "Screen printing RF antennas," 2016 17th International Symposium on Antenna Technology and Applied Electromagnetics (ANTEM), Montreal, QC, pp. 1-2, 2016.

[10] B. K. Tehrani, B. S. Cook and M. M. Tentzeris, "Inkjet Printing of Multilayer Millimeter-Wave Yagi-Uda Antennas on Flexible Substrates," in IEEE Antennas and Wireless Propagation Letters, vol. 15, pp. 143-146, 2016.

[11] K. Hettak, T. Ross, R. James, A. Momciu and J. Wight, "Flexible Polyethylene Terephthalate-based inkjet printed CPW-fed monopole antenna for $60 \mathrm{GHz}$ ISM applications," 2013 European Microwave Conference, Nuremberg, pp. 1447-1450, 2013.

[12] L. Yang et al., "RFID tag and RF structures on a paper substrate using inkjet-printing technology," Microwave Theory and Techniques, IEEE Transactions on, vol. 55, no. 12, pp. 2894-2901, Dec 2007. 
[13] A. Rahman and Y. Hao, "A novel tapered slot CPW-fed antenna for ultra-wideband applications and its on/off-body performance," International Workshop on Antenna Technology: Small and Smart Antennas Metamaterials and Applications, 2007.

[14] T. Aboufoul, A. Alomainy and C. Parini, "Reconfigured and Notched Tapered Slot UWB Antenna for Cognitive Radio Applications," International Journal of Antennas and Propagation, pp. 1-8, 2012.

[15] T. Aboufoul and A. Alomainy, "Reconfigurable notched Tapered Slot Ultra Wideband Antenna for Cognitive Radio applications," Proceedings of the 2012 IEEE International Symposium on Antennas and Propagation, 2012.

[16] S. F. Jilani, S. M. Abbas, K. P. Esselle and A. Alomainy, "Millimeterwave frequency reconfigurable T-shaped antenna for 5G networks," 2015 IEEE 11th International Conference on Wireless and Mobile Computing, Networking and Communications (WiMob), 2015.

[17] E. B. Secor, P. L. Prabhumirashi, K. Puntambekar, M. L. Geier and M. C. Hersam, "Inkjet Printing of High Conductivity, Flexible Graphene Patterns," The Journal of Physical Chemistry Letters, vol. 4, no. 8, pp. 1347-1351, 2013.

[18] A. Afyf, A. Elouerghi, M. Afyf, M. A. Sennouni and L. Bellarbi, "Flexible Wearable Antenna for Body Centric Wireless Communication in S-Band," International Conference on Electrical and Information Technologies, Rabat, Morocco, pp. 1-4, 2020.

[19] A. Takacs, S. Charlot, P. Calmon and D. Dragomirescu, "VHF/UHF Kapton supported antenna for cubesat applications," IEEE International Symposium on Antennas and Propagation \& USNC/URSI National Radio Science Meeting, San Diego, CA, pp. 2485-2486, 2017.

[20] Y. Fang and M. M. Tentzeris, "Chapter 1 - Surface Modification of Polyimide Films for Inkjet-Printing of Flexible Electronic Devices," Flexible Electronics, 2018.

[21] K.-Y. Shin, J.-Y. Hong and J. Jang, "Micropatterning of Graphene Sheets by Inkjet Printing and Its Wideband Dipole-Antenna Application," Advanced Materials, vol. 23, no. 18, pp. 2113-2118, 2011.

[22] S. Bandi, B. T. P. Madhav, D. K. Nayak and S. S. M. Reddy, "Compact flexible inkjet-printing antenna on paper and transparent PET substrate materials for vehicular instrument communication," Journal of Instrumentation, vol. 14, no. 10, P10022, 2019.

[23] S. Ahmed, F. A. Tahir, A. Shamim and H. M. Cheema, "A Compact Kapton-Based Inkjet-Printed Multiband Antenna for Flexible Wireless Devices," IEEE Antennas and Wireless Propagation Letters, vol. 14, pp. 1802-1805, 2015.

[24] I. Ibanez-Labiano and A. Alomainy, "Hybrid Metal-Graphene UltraWideband Antenna," International Conference on UK-China Emerging Technologies (UCET), Glasgow, United Kingdom, pp. 1-3, 2020.

[25] M. A. Monne, P. M Grubb, H. Stern, H. Subbaraman, R. T. Chen and M. Y. Chen, "Inkjet-Printed Graphene-Based $1 \times 2$ Phased Array Antenna," Micromachines, vol. 11, no. 9, pp. 863, 2020. 